\title{
Job load and hazard analysis: a method for the analysis of workplace conditions for occupational health care
}

\author{
MK MATTILA \\ From Tampere University of Technology, Occupational Safety Engineering, SF-33101 Tampere, Finland
}

ABSTRACT One requirement for successful occupational health care is reliable information on occupational hazards. The aim of this study was to develop a simple, standardised method for workplace investigations for use in occupational health care. The theoretical framework of the method comprises the stress-strain model, the hazard-danger model, and risk behaviour theory. The new method, termed job load and hazard analysis, includes four stages: identification of hazards, their evaluation, conclusions and proposals, and follow up. Different methods are available for hazard identification. The identification starts with a rough analysis of five factors, chemical hazards, physical hazards, physical load, mental stress, and accident risk. Hazards and stress factors are assessed with an ordinal scale. Specialised methods are used if all hazards cannot otherwise be identified. The analytical procedure comprises: (1) detection of hazards through observations and interviews at the workplace and with a questionnaire; (2) assessment of findings as teamwork; and (3) evaluation of the results of these assessments to yield conclusions and proposals made by occupational health care personnel. A data processing system has been developed for data storage् and future use. The method has functioned in practice, improving the contents of the occupationat health care programme and generating preventive measures. The method offers many new possio bilities for controlling occupational hazards and studying relations between working conditions and workers' health.

The Finnish Occupational Health Care Act came into force in stages and its implementation should have been fully completed by the end of March 1983. The Act obligates employers to provide occupational health care for employees and to prevent health hazards at work.

The Occupational Health Care Act requires workplace investigations for the analysis of hazards inherent in the work and working conditions. The results of workplace investigations are used to plan medical examinations and other occupational health care services. Occupational medicine itself has long traditions, but workplace investigations as the basis of occupational health care is a new concept first defined in the Act. Thus occupational health personnel lacked the training to analyse jobs and working conditions, nor were guidelines available. It soon became evident

Received 17 December 1984 Accepted 28 January 1985 that workplace inspections were a central problem hindering enforcement of the Act.

New methods have been developed for some aspects of workplace investigations particularly for ergonomic $^{1-3}$ and psychological ${ }^{4-6}$ analyses. The need for a comprehensive job analysis has been reported and several new, structured methods have been devised for job analysis. ${ }^{7-9}$

Many of the current methods are limited in scope and object, are too complex for use as an everyday tool, and do not as such meet the needs of occupational health care. Additional problems arise with regard to small enterprises and highly varying work, construction work, for example. The objective of the present study was to develop an easy and standardised method for the analysis of jobs and workplace conditions for occupational health care.

\section{Theoretical basis}

For this study the stress-strain concept, the hazarddanger model, and the risk behaviour theory were 
selected as the theoretical basis; the approach used in job analysis was applied.

Current practice was also taken into consideration in the study, as it may contribute valuable information about an approach tested in practice. ${ }^{10}$ The present state of the art was investigated in several ways. Questionnaires were sent to occupational safety managers, I visited seven occupational health care units, and 24 workplace analysis forms used in Finland were compared. ${ }^{11}$

The stress-strain concept adapted from mechanics is useful for work analysis. Different energies and stressors at work affect man and cause reactions. Strain also depends on individual factors. ${ }^{12}$ Stress may originate from any element in man-machine systems or man's interface with them. ${ }^{913}$ The stressstrain concept is equally applicable for physical, ${ }^{12}$ psychososial, ${ }^{7}$ and chemical factors. ${ }^{14}$

The hazard-danger model (Gefahr-Gefährdung) has proved its value for the investigation and prevention of occupational accidents. ${ }^{15-17}$ Hazard is defined as a condition that has the potential to cause adverse effects such as injury or material loss. Danger is defined as relative exposure to a hazard. ${ }^{18}$ In accident prevention it is important to control hazards so that risk is minimised. If hazards cannot be controlled safety essentially depends on human behaviour. ${ }^{17}$

Hazards and stresses alone are insufficient to explain the occurrence of injuries and illness at work. Much depends on risk behaviour which is concerned with man's performance under different conditions, the reception of information, decision making, and the choice of actions. Risk assessment is individual and depends on the situation. ${ }^{1617}$ Risk behaviour is especially important to workplace investigations in the planning and implementation of preventive measures.
Job analysis has proved to be valuable for the description and analysis of work. ${ }^{89}$ Job analysis is the process of obtaining information about jobs and involves a two stage process:

(1) Elucidation of the information from a source by, for example, observing and interviewing a newcomer to the job or by having the worker report such information himself.

(2) The organisation and presentation of information in the desired form.

The aim of this paper is to present a new, simple, and standardised method for workplace investigations for occupational health care. The method is best suited for determining the contents of the occupational health care programme and for preventing health hazards at the workplace.

\section{Workplace investigations: aims and requirements}

\section{CONCEPT}

The objective of workplace investigations is to prevent health hazards at work. To attain this objective, the investigation must include different stages: the identification of health hazards, the evaluation of these hazards, conclusions and proposals for preventive measures, and the follow up of developments.

\section{A I MS}

The aims of the method for workplace investigations are: (1) identification of the health hazards to which workers are exposed in their work and by their working conditions; (2) to help determine the contents of the occupational health care programme according to the real needs that arise from jobs and working conditions; and (3) to support the prevention of hazards

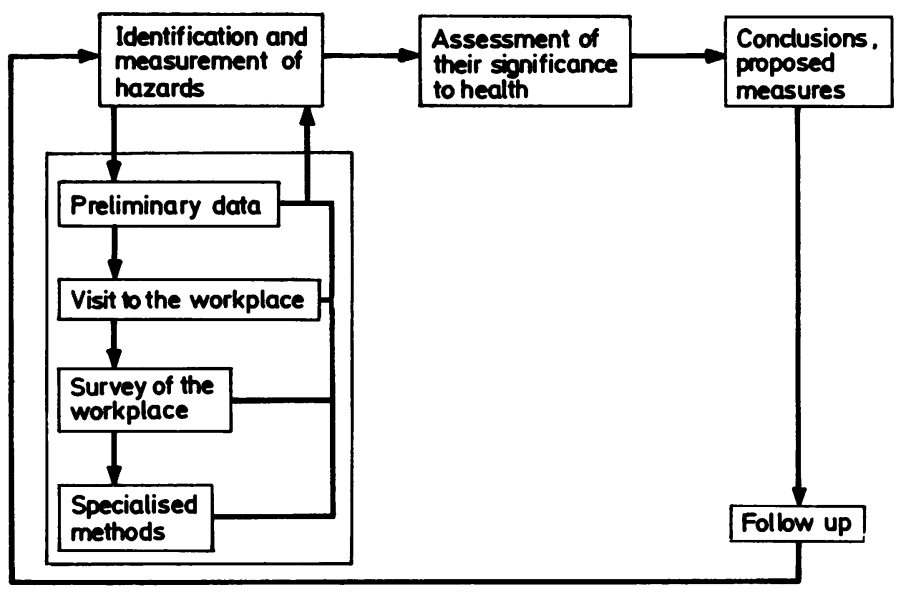

Fig 1 Structure of the method. 
Table 1 Rating scale for the preliminary job hazard analysis

\begin{tabular}{|c|c|c|}
\hline \multirow[t]{2}{*}{ Item } & \multicolumn{2}{|c|}{ Rating scale } \\
\hline & To some extent: may affect health & Much load or many hazards; definite effect on health \\
\hline Chemical hazards & $\begin{array}{l}\text { Occasional exposure to below half hygienic } \\
\text { standard, brief peaks, long term effects not } \\
\text { suspected, cause is recognised at workplace }\end{array}$ & $\begin{array}{l}\text { Exposure to hygienic standard, long term effects } \\
\text { for example, allergenic or carcinogenic suspected, } \\
\text { effects on health are known }\end{array}$ \\
\hline Physical hazards & $\begin{array}{l}\text { Exposure below level known to affect health, } \\
\text { problem is recognised at workplace }\end{array}$ & $\begin{array}{l}\text { Exposure above level known to affect health, } \\
\text { complaints recorded, effects on health are known }\end{array}$ \\
\hline Physical load & $\begin{array}{l}\text { At most work is moderately heavy, peak } \\
\text { loads are seldom, repetitive work sometimes } \\
\text { causes muscle load, brief periods of postural } \\
\text { load, problems connected with ergonomic } \\
\text { stress are recognised at workplace }\end{array}$ & $\begin{array}{l}\text { Heavy dynamic or static work, unusual body } \\
\text { postures, heavy weights handled often while } \\
\text { standing, continuous repetitive work, peak loads } \\
\text { common, ergonomic stress leads to complaints of } \\
\text { pains }\end{array}$ \\
\hline Mental stress & $\begin{array}{l}\text { Monotonous or sometimes forced paced work, } \\
\text { some solitary work, time pressure may occur, } \\
\text { some responsibility for safety or productivity }\end{array}$ & $\begin{array}{l}\text { Continuous monotonous or forced paced work, } \\
\text { solitary work or time pressure for most of working } \\
\text { hours, much responsibility for safety or productivity }\end{array}$ \\
\hline Accident risk & $\begin{array}{l}\text { Satisfactory housekeeping, some safeguards, } \\
\text { some danger of falling or slipping, unclear } \\
\text { walkway markings, insufficient illumination, } \\
\text { insufficient consideration given to accident } \\
\text { prevention in materials handling, ineffective } \\
\text { maintenance, personal protective equipment } \\
\text { only partly used and not fully well maintained }\end{array}$ & $\begin{array}{l}\text { Poor housekeeping, safeguards lacking, greater } \\
\text { danger of falling or slipping, few or no walkway } \\
\text { markings, poor illumination, little attention paid } \\
\text { to accident prevention in materials handling; no } \\
\text { systematic programme for repair and maintenance, } \\
\text { personal protective equipment is lacking or provides } \\
\text { insufficient protection }\end{array}$ \\
\hline
\end{tabular}

and to facilitate the selection of appropriate preventive measures.

The method of analysis must also meet specific requirements. ${ }^{19}$ The following requirements were set for this new method:

Reliability - The results must be reliable. Guidelines for the practical realisation and assessment training enhance the reliability of the method. Thus the method must be standardised.

Qualitativeness and quantitativeness-The method should analyse the factors not only qualitatively but also quantitatively so far as possible.

Coverage and flexibility - The method should cover all the employees and all the hazards at the workplace. It should be possible to analyse all jobs and all situations that affect preventive measures.

Simplicity - The method should be so simple that the personnel at the workplace and not only occupational safety and health personnel are able to use it after a short training period.

Economy-The method should be economical enough to allow its use in practice.

\section{METHOD DEVELOPMENT}

The present state of the art was investigated in several ways. Questionnaires were sent to 233 occupational safety managers, I visited seven occupational health care units, and 24 workplace analysis forms used in Finland were compared.

The initial version of the method was created on the basis of the investigation of the present state of the art and the occupational safety and health reports described earlier. The items were selected so that, according to the theoretical background, they covered all factors relevant to workers' health and safety and so that they concerned most of the usually analysed jobs.

The rating scale was selected to be relevant to thee needs of occupational health care and to the need for preventive measures. An ordinal scale was applied because of the positive experiences reported in other studies. ${ }^{5792021}$

The initial version of the method was tested in an-市 alyses done by 300 students attending classes in occupational safety at the university. This test pro-oㅡㅁ vided experience about the utility and reliability of the method. The initial method was also used by two occupational health care units at several workplaces. Their comments and experiences were also taken into account when the method was revised. The modified 3 version was analysed and discussed further with the participants from the workplaces and with the occupational health personnel, after which the method attained its present form and was accepted as $₹$ an occupational health care tool ready for practical 음 testing in construction work.

\section{METHOD}

The new method, called job load and hazard analysis comprises the identification of health hazards, their 0 evaluation, conclusions and proposals concerning measures to be taken, and follow up. Different meth-o ods are available for identifying health hazards. More specialised analytical methods are available when alE the hazards cannot be identified otherwise. Specialised? methods may be needed for problems concerned with 
industrial hygiene, ergonomics, or mental stress. The method is outlined in fig 1.

\section{INFORMATION ALREADY AVAILABLE}

The workplace personnel may already have collected information useful for occupational health care. Such data may be gathered with a checklist (see appendix 1).

PRELIMINARY JOB HAZARD ANALYSIS

The purpose of the preliminary job hazard analysis is to provide a summary of the loads and hazards of jobs and to provide the basis for the consideration of preventive measures or specialised analyses. The preliminary job hazard analysis comprises different types of loads and hazards as such. Therefore the items cover the most common hazards and loading factors, and the number of items is kept as small as possible (see appendix 2 and table 1).

\section{GENERAL JOB HAZARD ANALYSIS}

The general job hazard analysis applies a more detailed job analysis in cases when all the hazards cannot be sufficiently well identified by the preliminary job hazard analysis. It is so called because it provides the level of details usually required of safety surveys in Finland. The general job analysis consists of 34 items grouped according to the man-machine model. The form appears in appendix 3.

\section{Procedure of analysis}

The flow of information collection and processing is the same as for the preliminary job hazard analysis with respect to the basic information, which is then supplemented with more detailed data as necessary. Decisions regarding the need for supplementary methods are made during the information processing, and initiatives are made accordingly (fig 2).

The object of job analysis is several positions, similar enough to justify being covered by a single analysis. One or many people may work at the same job. Once all the jobs in the organisation have been analysed, a review of the circumstances that affect the entire personnel is ready to hand.

The preliminary job hazard analysis is used during an investigation tour of the workplace. The investigation is done by a team that comprises occupational health care personnel, the safety manager or engineer, who represents management, and the occupational safety delegate, who represents labour. Each team member makes his own analysis independently through observations and interviews, and the results of analysis is written on the form.

The preliminary job hazard analysis may also be done as a worker questionnaire. Then each worker assesses for himself the hazards and stress factors in his own job. The form has now been developed further; the workers' personal experiences with their current jobs are inquired of, each item being illustrated by concrete examples of different hazards and stress factors. The workers may also point out factors of current interest and make comments and proposals.

MEETING OF THE COOPERATION TEAM

The individual results are discussed by the cooperation team, which consists of the participants in the

(a) Preliminary job hazard analysis

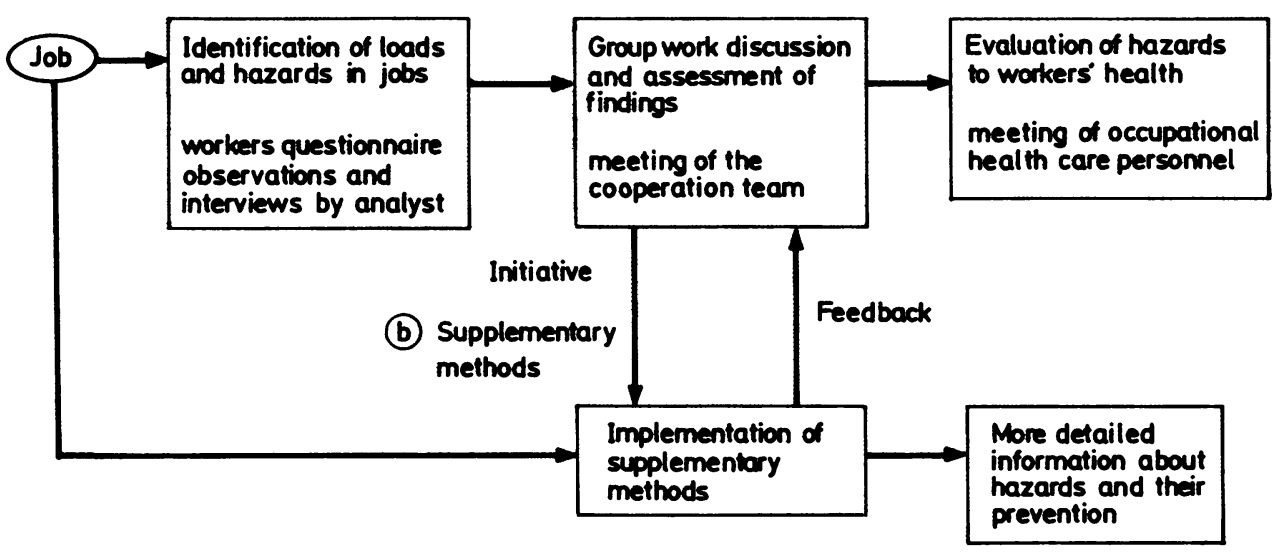

Fig 2 Stages in information collecting and processing by different methods of analysis. 
investigation and possibly of line management representatives. All the jobs analysed during the investigation are discussed and assessed together. This procedure yields a group assessment of the hazards and loads of jobs. All proposals for further analysis or preventive measures are written down on the form.

\section{EVALUATION OF HAZARDS}

The occupational health care personnel then evaluate the stress and hazards of jobs independently on the basis of the information collected during the investigation and after the meeting of the cooperation team. Particular emphasis is placed on assessing the significance of the findings to workers' health and safety. This assessment yields conclusions and proposals.

\section{CONCLUSIONS AND PROPOSALS}

The conclusions and proposals made by the occupational health care personnel are the main result of the workplace investigation. They will be used to formulate the occupational health care programme for the workplace and to determine the need for other occupational health care services.

The conclusions and proposals should pay special attention to jobs with the highest hazard ratings. These workers' occupational health care and prevention of the hazards in their jobs should be given priority. These proposals are supplied to the line management in written form. A special meeting to show the final results is advisable.

FOLLOW UP

Workplace investigation is a continous process. The

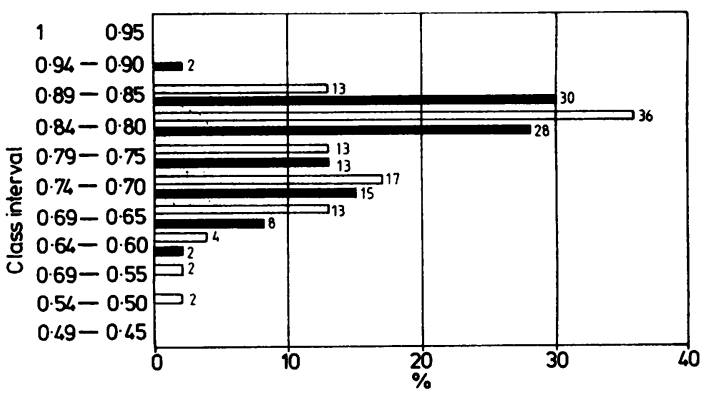

Occupational health physician / occupationa health nurse 1

Occupational health physician/occupational health nurse 2

Fig 3 Reliability (as distribution of coefficients) of three analysts' assessments of 53 jobs with general job hazard analysis. cycle of analysis should be repeated periodically so $\overline{\bar{\alpha}}$ that changes in jobs and working conditions may be $z$ monitored. During the analytical procedure, a stock ${ }_{0}^{\mathbb{Q}}$ of available information is acquired which is the basis for follow up.

An automatic data processing system has been seto up to process all the information gathered by the음 method. Data processing opens up new possibilities for using the information and for studying the relations between work and health. The morbidity of workers with different jobs may easily be compared ${ }^{\text {s }}$ with circumstances related to work. Data processing. also makes it possible to build up an organisational $\overrightarrow{\vec{\omega}}$ memory bank, which then allows the use of compara- $\omega$ ble experiences of workplaces that would otherwise encounter insurmountable difficulties.

\section{RELIABILITY}

The reliability of job related data for any given job or jobs generally refers to the extent to which differentک analysts at the same time or the same analyst ato different times elicit consistent information.

The reliability of the preliminary job hazard an- $\bar{O}$ alysis was tested experimentally. Working simultaneously and independently, two experienced analysts, one nurse, and one occupational safety engineer an- alysed 32 jobs at a construction firm. The coefficients $\overrightarrow{0}$ of reliability ${ }^{22}$ for different items weê: o $r_{\text {chemical }}=0.91, r_{\text {physical }}=0.91, r_{\text {ergonomical }}=0.9$ $r_{\text {mental }}=0.87$, and $r_{\text {accidental }}=0.94$.

The reliability of the general job hazard analysis was determined in an experiment, where one? occupational health physician and two occupational $\stackrel{\circ}{\mathbb{Q}}$ health nurses simultaneously and independently an- $\varrho$ alysed 53 tasks at several construction sites. The aver-음 age coefficient or reliability ${ }^{22}$ was $r=0 \cdot 78$. Figure 33 shows the distribution of coefficients for the tasks analysed.

The agreement between the assessments of workers and a safety specialist was determined for the workers' $?$ questionnaire and ratings made by an occupational $\frac{0}{3}$ health nurse. The workers and the occupational health nurse made their assessments independently at $ᄋ$ the same construction site on the same day. The

Table 2 Equality of ratings by employees (3) and an occupational health nurse when using the preliminary job hazard analysis to analyse 15 jobs (test statistic for a fixed $\mathrm{N}$ number of matched samples)

\begin{tabular}{|c|c|c|c|}
\hline Loads and hazards & $D^{-}$ & $t_{14}$ & $\mathbf{p}$ \\
\hline $\begin{array}{l}\text { Chemical hazards } \\
\text { Physical hazards } \\
\text { Physical load } \\
\text { Mental stress } \\
\text { Accident risk }\end{array}$ & $\begin{array}{l}-0.40 \\
-0.13 \\
-0.47 \\
-0.53 \\
-0.40\end{array}$ & $\begin{array}{l}-0.68 \\
-0.25 \\
-0.92 \\
-1.05 \\
-0.63\end{array}$ & $\begin{array}{l}\text { NS } \\
\text { NS } \\
\text { NS } \\
\text { NS } \\
\text { NS }\end{array}$ \\
\hline
\end{tabular}


Table 3 Agreement (Kappa) of the ratings by safety and health professionals and the cooperation team when using preliminary job hazard analysis

\begin{tabular}{lll}
\hline Loads and hazards & $\begin{array}{l}\text { Occupational health } \\
\text { nurse/cooperation } \\
\text { team }(n=66)\end{array}$ & $\begin{array}{l}\text { Occupational safety } \\
\text { engineer/cooperation } \\
\text { team }(n=66)\end{array}$ \\
\hline Chemical hazards & 0.58 & 0.47 \\
Physical hazards & 0.66 & 0.55 \\
Physical load & 0.76 & 0.60 \\
Mental stress & 0.63 & 0.38 \\
Accident risk & 0.59 & 0.55 \\
\hline
\end{tabular}

occupational health nurse's assessments were compared with the assessments of three randomly selected workers with the same job. The difference in assessments were tested with the $t$ test for a fixed number of matched samples with ordinal outcome. ${ }^{23}$ The differences were not statistically significant (table 2).

The agreement of assessments between safety specialists and the meeting of the cooperation team was determined with the Kappa test. ${ }^{24}$ The assessments of the same jobs at the same site made by the occupational health nurse and by the meeting of the cooperation team were compared. Good agreement on all the items was found between the occupational health nurse and the meeting of the cooperation team (table 3).

\section{VALIDITY}

The concept of validity refers to the essential correctness of the information obtained. In this study, where the practical test of the method was done in the construction industry, the only available criteria were found in a study carried out in Sweden. ${ }^{25}$ When the differences in the method of analysis are taken into account and when some differences in working environment and technology are assumed, the comparison proved that almost all the hazards and stress factors detected by the method under study corresponded with those in the Swedish study. Since a major portion of the analysis is documentary in nature, it logically follows that the result is valid. It is also possible here to evaluate validity from the results concerning reliability. ${ }^{2627}$

\section{PRACTICAL OBSER VATIONS}

The new method has been proved to function in practice. It has been tested in occupational health care in the construction industry for two years now. The workers have shown themselves to be active on the questionnaire, as the response rate has been from $80 \%$ to $97 \%$. The content of occupational health care has become more precise. Preventive measures have been proposed more often than before, and they have been more comprehensive. Representatives of labour, management, and health and safety personnel have been willing to participate in the meeting of the cooperation team. Confidence in occupational health care seems to have increased. The observations made during workplace investigations have been used to train new workers and to educate supervisors. The observations have also been studied during the planning stages of a new construction project.

\section{Discussion}

This new method for workplace investigations has the following characteristics:

(1) Job analysis makes it possible to analyse all working conditions. This approach proved to be practical in linking information about hazards and stress to the contents of occupational health care.

(2) The cooperative approach is realised through a cooperation team that evaluates the gathered information. The cooperation team contributes the advantages of group problem solving. The results become more comprehensive, different personnel groups are concerned in the process and have the chance to express themselves, the necessary cooperation takes place, and the acceptability of and confidence in the assessment improves. In several other studies the cooperative approach has also proved to be fruitful in preventing accidents. ${ }^{2829}$

(3) Workers' active role in hazard detection guarantees that all the problems recognised at the workplace come up for closer consideration. Workers have proved themselves ready to play an essential part in identifiying hazards. ${ }^{1630}$

(4) The independent role of occupational health care personnel is further strengthened when they make assessments independently, and when their conclusions and proposals are reflected in the contents of the occupational health care programme.

The method was tested for two years at a construction site, where it was applied as part of the actual occupational health care. The method worked out well and provided a concrete basis for the occupational health care programme. It was found possible to use the method to determine the contents of an occupational health care programme. The systematic analysis clearly eliminated the common drawbacks and inadequacies found in previous methods. It also had numerous indirect, special advantages: proposals for measures to eliminate unsatisfactory working conditions were more numerous and of better quality, cooperation between occupational health care and occupational safety received an efficient forum, workers' confidence in the analysis increased, and the analysis had an invigorating effect on all occupational safety activities at the site and obviously had a positive effect on its safety climate.

The method for the workplace investigation offers numerous possibilities for the utilisation of informa- 
tion. Most of the utilisation occurs in occupational health care, where the information is useful in the initial medical examinations of new workers, in advising workers about safe performance, and in studies on the relations between working conditions and workers' health status. But the information also has other uses - for example, in preventing hazards during planning, in production design, and in management. Systematic workplace investigations may be one part of the information system of organisation and may help the management in guiding the system, thereby contributing to the realisation of safety objectives.

This study was supported by a grant from the Academy of Finland. The author wishes to thank Jorma Saari for his continued encouragement through all phases of the work and Sheryl Hinkkanen for correcting the English.

\section{References}

${ }^{1}$ Schmidtke H. Ergonimische Betwertung von Arbeitssystemen, Entwurf eines Verfahrens. Munich: Carl Hanser Verlag, 1976.

${ }^{2}$ Karhu O, Kansi P, Kuorinka I. Correcting working postures in industry: a practical method for analysis. Applied Ergonomics 1977;8:199-201.

${ }^{3}$ Holzmann P. Arban - a new method for ergonomic effort. Applied Ergonomics 1982;13:82-6.

${ }^{4}$ Hackman JR, Oldham GR. The job diagnostic survey: an instrument for the diagnosis of jobs and the evaluation of job redesign projects. Princetown: Yale University, 1974. (Department of administrative sciences, technical report No 4.)

${ }^{5}$ Fleishman EA. Taxonomic problems in human performance research. In: Singleton WT, Spurgeon P, eds. Measurement of human resources. London: Taylor and Francis, 1975:49-72.

${ }^{6}$ Hacker W. Spezielle Arbeits- und Ingenieurpsychologie. Psychologische Bewertung von Arbeitsgestaltungmassnahmen 1. Berlin: VEB Deutscher Verlag der Wissenschaften, 1980.

${ }^{7}$ Frieling E, Hoyos CG. Fragebogen zur Arbeitsanalyse (FAA), Deutsche Bearbeitung des "Position Analysis Questionnaire" (PAQ). Handbuch. Berne Stuttgart, Vienna: Verlag Hans Huber, 1978.

${ }^{8}$ McCormick EJ. Job analysis: methods and applications. New York: A Division of the American Management Associations, 1979.

${ }^{9}$ Rohmert W, Landau K. A new technique for job analysis. London: Taylor and Francis Ltd, 1983.

${ }^{10}$ Campbell DT, Stanley JC. Experimental and quasi-experimental designs for research. Chicago: Rand McNally College Publishing Company, 1966.

${ }^{11}$ Mattila M. The survey of the workplace for occupational health care-development and practical testing of method. Tampere: Tampere University of Technology, 1984. (Publications 26.) (In Finnish with an English abstract.)

${ }^{12}$ Schmidtke H. Lehrbuch der Ergonomie. Munich: Carl Hanser Verlag, 1981.

${ }^{13}$ Fraser TM. Human stress, work and job satisfaction. Geneva: International Labour Office, 1983. (Occupational safety and health series 50 .)

${ }^{14}$ Atherley GC. Occupational health and safety concepts, chemical and processing hazards. London: Scientific Publishers, 1978.

${ }^{15}$ Skiba R. Taschenbuch Arbeitssicherheit. Bielefeld: Eric Schmidt Verlag, 1979.

${ }^{16}$ Zimolong B. Risikoeinschätzung und Unfallgefährdung beim Rangieren. Zeitschrift für Verkehrisicherheit 1979;25:109-14.

${ }^{17}$ Hoyos CG. Psychologische Unfall-und Sicherheitsforschung. Stuttgart: Kohlhammer, 1980.

${ }^{18}$ Hammer W. Occupational safety management and engineering. 2nd ed. Englewood Cliffs, NJ: Prentice-Hall, 1981.

19 Johnson WG. MORT safety assurance systems. New York: Marcel Dekker, Inc, 1980.

${ }^{20}$ McCormick EJ, Mecham RC, Jeanneret PR. Technical manual for the position analysis questionnaire (PAQ). West Lafayette: Purdue University, 1972.

${ }^{21}$ Frieling E. Psychologische Arbeitsanalyse. Stuttgart: Kohlhammer, 1975.

${ }^{22}$ Finn RH. A note on estimating the reliability of categorical data. Educational and Psychological Measurements 1970;30:71-6.

${ }^{23}$ Nurminen M, Järvinen E, Mutanen P. Simple test statistics for a fixed number of matched samples with ordinal outcome variables. Biometrical Journal 1983;4:393-400.

${ }^{24}$ Fleiss JL. Statistical methods for rates and proportions. 2nd ed. Nee York: John Wiley, 1973.

${ }^{25}$ Miljöbeskrivning av sysselsättningar inom byggbranchen. Stock holm: Rapport frản Bygghälsan, 1976.

${ }^{26}$ Ebel RL. Estimation of the reliability of ratings. Psychometricto 1950;16:407-24.

${ }^{27}$ Rohmert W, Landau K. Das Arbeitswissenschaftliche Erhebungsverfahven zur Tätigeitsanalyse (AET). Handbuch. Berne: Verlag Hans Huber, 1979.

${ }^{28}$ Menckel E. Utreckling av rutiner $i$ olycksfallsförebyggande arbete. Försöksverksamhet $i$ ett företag. Stockholm: Arbetarskyddsstyrelsen, 1981; Undersökningsrapport 1981:24.

${ }^{29}$ Kjellén U. Analysis and development of corporative practices for accident control. Stockholm: Royal Institute of Technology, 1983. (Rapport TRITA-AVE-0001.)

${ }^{30}$ Kaplan MC, Coleman PJ. County highway department hazards: a comparative analysis of inspection and worker detected hazards. Madison, Wisconsin: State of Wisconsin, Department of Industry Labor and Human Relations, 1976. 
Appendix 1

JOB LOAD AND HAZARD ANALYSIS: CHECKLIST FOR INFORMATION ALREADY AVAILABLE

Item

Information already available

Yes

No
Answer: where is the information, how is the issue being managed?

1 Identification of the workplace:

Company

Address and phone number

Branch

Workplace

Address

Contact person

Time of the project

2 Description of product:

Product

Production technique

Current stage

Plans for the worksite

3 Manpower:

Workers

Supervisors, leadership

Women

Young workers

Subcontractors

4 Machines and equipment:

List of machines at the plant

Periods used

Exposed persons

5 Chemicals:

Agents hazards to health

Carcinogenic agents

Safety sheets

Amounts used

Users, exposed persons

6 Occupational safety activity:

Meetings of safety committees

Internal safety inspections

Industrial hygienic measurements

Inspections of safety authorities

7 Safety surveys, job descriptions:

Workplace investigation

Ergonomic survey

Job training

8 Occurrences of illness and injuries:

Occupational diseases

Other work related diseases

Accident statistics

9 Current occupational health care:

Provision of adequate information

Medical examinations

Personal protective equipment

First aid

Follow up of handicapped workers 
Appendix 2

PRELIMINARY JOB HAZARD ANALYSIS FORM

Job load and hazard analysis

Company

Workplace

Preliminary job hazard analysis

Date

Analyst

Occupation

Job

Task

Number of employees

\section{Analyst}

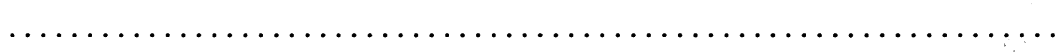




\section{Appendix 3}

JOB LOAD AND HAZARD ANALYSIS FORM: JOB DESCRIPTION AND ASSESSMENT FORM

Position:

Company:

Job:

Worksite:

Task:

Analyst:

Date:

Item

Rating scale

Comments

$\begin{array}{llll}0^{\mathrm{a}} & 1^{\mathrm{b}} & 2^{\mathrm{c}} & 3^{\mathrm{d}}\end{array}$

A WORK ENVIRONMENT

1.1 Steady state noise

1.2 Impulse noise

1.3 Whole body vibration

1.4 Vibration transmitted to hands

1.5 Pressure

1.6 Illumination

1.7 Glare

1.8 Radiation

1.9 Temperature

1.10 Humidity

1.11 Air draughts

1.12 Climate

Chemical and biological factors:

2.1 Products and agents hazardous to health

2.2 Carcinogenic agents

2.3 Air contaminants

2.4 Biological factors

Psychological factors:
3.1 Workhours
3.2 Forced pace
3.3 Solitary work
3.4 Responsibility

B WORK ACTIVITY

4.1 Dynamic muscle load

4.2 One sided muscle load

4.3 Static muscle load

4.4 Stress due to control operations

4.5 Need for precision

4.6 Complexity of decision making

4.7 Monotonous work

C POSTURES AND THE WORKSITE
5.1 Anthropometric design
5.2 Work postures

5.3 Accessibility of the worksite 
Item

Rating scale

Comments

$\underline{\underline{c}}$

Item

Rating scale

$\begin{array}{llll}0^{\mathrm{a}} & 1^{\mathrm{b}} & 2^{\mathrm{c}} & 3^{\mathrm{d}}\end{array}$

D TECHNICAL SAFETY

6.1 Safety engineering at work

6.2 Rescue operations

E REQUIREMENTS FOR THE WORKER

7.1 Health requirements

7.2 Training, information, and educational requirements

${ }^{a}$ Does not apply.

'Some disturbance to comfort at work.

${ }^{\mathrm{c} H i n d e r s}$ work performance and the utility of the occupational system.

${ }^{\mathrm{d}}$ Clear health risk or may even lead to fatalities. 